\title{
The Mediating Role of Growth Mindset in the Causal Model of the Factors Affecting the Mathematics Learning of Ninth-Grade Students
}

\author{
Suntonrapot Damrongpanit \\ Department of Educational Foundations and Development, Faculty of Education, Chiang Mai University, Thailand
}

Received September 5, 2020; Revised November 1, 2020; Accepted November 11, 2020

\begin{abstract}
Cite This Paper in the following Citation Styles
(a): [1] Suntonrapot Damrongpanit, "The Mediating Role of Growth Mindset in the Causal Model of the Factors Affecting the Mathematics Learning of Ninth-Grade Students, "Universal Journal of Educational Research, Vol. 8, No. 12, pp. 7183-7196, 2020. DOI: 10.13189ujer.2020.081285.
\end{abstract}

(b): Suntonrapot Damrongpanit (2020). The Mediating Role of Growth Mindset in the Causal Model of the Factors Affecting the Mathematics Learning of Ninth-Grade Students. Universal Journal of Educational Research, 8(12), 7183-7196. DOI: 10.13189ujer.2020.081285.

Copyright $\bigcirc 2020$ by authors, all rights reserved. Authors agree that this article remains permanently open access under the terms of the Creative Commons Attribution License 4.0 International License

\begin{abstract}
The objectives included examining the mediation role of growth mindset as the causal model of the factors affecting mathematics learning outcomes of 514 ninth grade students who were measured by the national standardized scores rubric. Two models with a relationship structure of two different variables were compared: (model A) the model without a growth mindset; and the growth mindset as the mediating variable as (model B). The research tools comprised of 1) Questionnaires on factors of Growth Mindset, Achievement Motivation, Attitude towards Mathematics, Mathematical Self-Efficacy, Background Knowledge, and Mathematical Achievement with a five-point Likert scale pattern, and 2) Mathematics Aptitude test. The obtained data was analyzed by Path and Mediation analysis with Mplus 7.4 program. It was concluded that the model with a Growth Mindset as a mediating variable between factors and mathematics grades was most consistent with empirical data. The background knowledge had the highest indirect and total effect, while mathematical aptitude had the most direct effect on mathematics learning outcomes. Additionally, the growth mindset was statistically significant and had a positive direct effect on mathematics learning outcomes. All factors in the model were jointly able to explain the variance in mathematics learning outcomes by $82.90 \%$. It also revealed that growth mindset played a role as a partial mediation in achievement motivation, mathematics background knowledge and
\end{abstract}

particularly in mathematics aptitude. Therefore, the growth mindset did not only influence Mathematics learning outcomes but it also had the positive relationship linking to each key factors that helped promote students to have better performance.

Keywords Mediation, Growth Mindset, Interaction Effect, Causal Relationship, Mathematics Achievement

\section{Introduction}

The ability to learn mathematics involves many important factors. Each part can explain academic success in different contexts $[1,2]$. Even though the findings of past research have revealed more prominent key variables with more limitations, the correlation structure between complex variables still has difficulty for understanding.

In recent years, a growth mindset has gained attention to the study of individual success predictions [3, 4] and found that not only are the key factors affecting effective learning of mathematics but also interacting with some factors that influence mathematics learning in the mediation effect $[5$, 6]. However, these findings have a lack of linkage between how the growth mindset influences in the same effect as variables that often influence mathematical learning results. This will lead to knowledge boundary expansion 
and increase knowledge clarity for the development of learning management continuing support for students both inside and outside the classroom.

\subsection{Factors Affecting Mathematics Achievement of Students}

Many researchers introduce research findings on various factors that influence mathematic achievement. Even though there is the clarification of the mathematical learning results in different contexts, most of the research findings showed five key factors explaining the ability to learn mathematics within the learners as;

Background Knowledge is a concept arising from individual experiences which applied for understanding each content with memory usage or recalling the knowledge. It can lead to understanding other related contents. It helps in using the abilities of complex content and visual information processes with ease, especially learning mathematics [7]. Background Knowledge frequently performs a powerful influence on mathematics learning in a longitudinal study and shows an important role in learning ability. Several past studies have described the influence of the ability to apply previous knowledge to learn new content, such as Froiland and Davison [8], who found that mathematics achievement of the $9^{\text {th }}$-grade students had a positive influence on mathematics achievement of $12^{\text {th }}$ grade students. Putwain et al. [9] discovered that mathematics achievement for $9^{\text {th }}$ grade students had a positive influence on mathematics achievement of $12^{\text {th }}$ grade students. Moreover, Prast et al. [10] revealed that the $1^{\text {st }}$ mathematics achievement scores had a positive influence on the $3^{\text {rd }}$ mathematics achievement of the $2^{\text {nd }}$ to $6^{\text {th }}$ grade students in all skill levels (low, average, high), like Putwain et al. [9] indicated that the $1^{\text {st }}$ mathematics achievement scores had a positive influence on the $5^{\text {th }}$ mathematics achievement of the $5^{\text {th }}$ to 6 th-grade students. They noted that when using factors of background knowledge into groups of independent variables for mathematic learning achievement prediction, it cannot use only to predict at a good level. It also interacts with other independent variables, and then influences mathematics achievements, such as achievement motivation [8], self-efficacy [10, 11], and academic aptitude [12], etc.

Achievement motivation is a name for calling a modern psychology group that describes the ability to focus on one's success [13]. Learning psychologists say that achievement motivation is a good predictor in describing students' learning. It explains that achievement motivation is a need for achievement or achievement, and fear of failure $[14,15,16]$. Learners with achievement motivation will have goal-oriented work power including maintaining the action level to achieve desired goals consistently [17]. Therefore, encouraging learners to strengthen achievement motivation in learning together with effective teaching will lead to more expected outcomes than developing learners with a low level of achievement motivation. According to the previous research data, Sriphai et al. [18], Pitsia et al [19], Froiland and Davison [8], found that achievement motivation is a crucial factor that can explain the development of mathematics achievement among high school students for both short and long term. It is consistent with Rhew et al. [6], who revealed that motivation influences the achievement of high school students. Moreover, Damrongpanit [20] found that achievement motivation is not only a factor influencing mathematics achievement but also interacts with attitude toward mathematics of the $9^{\text {th }}$-grade students as mediator and Dinkelmann and Buff [1] discovered that achievement motivation interacting with competence belief jointly affects the mathematics achievement of students aged 7-13.

Attitude toward Mathematics is a fundamental factor in explaining the likelihood of various behaviors for each individual. As in theory, an attitude refers to personal interests that is the desire to know, like, wait, or be involved in something. Attitude comprises of three important components as belief, pleasant feeling, and impressive experience [21]. Consequently, instructional management can stimulate the students to have belief, good feeling, and have an impressive experience with learning leading to cooperation and instructional achievement $[22$, 23, 24]. As a result, researchers often consider an attitude toward mathematics as a predictor of ongoing academic success [25]. The recent findings by Damrongpanit [20] showed that when teachers provide quality of learning experiences for good learners, namely 1) planning and preparing instruction, 2) promoting the environment and enhancing good relationship, 3) applying teaching strategies based on learner's experience, 4) apply appropriate media, technology for learning content and goals, and 5) use of the measurement and evaluation of learning to improve learners, good instructional management does not affect only mathematics achievement of the $9^{\text {th }}$ grade students, it also affects attitude toward mathematics, achievement motivation, and mathematics self-efficacy before affecting mathematics achievement. The mentioned factors can explain the variance of the mathematics achievement of students to $60.5 \%$. The findings have consistency with Pitsia et al. [19] that the relationship of all three factors affected mathematics achievement. For this reason, researchers in many disciplines consider applying an attitude to explain the effects on the learners in various knowledge and desirable behaviors for science reading [25], and perception of creative reading [26] and digital technology [27], etc.

Self-efficacy refers to beliefs about one's own ability to cope or deal with problems through the adaptation of cognitive strategies and self-regulation [28]. It is a part of personal awareness of the special ability to make estimates about managing things with effective accomplishment [29, 15]. It can be expressed as the behavioral observations of 
the involvement of the learning effort in thinking, hard working, and patience to achieve results from your best efforts [28, 30]. For this reason, many scholars have said that self-efficacy is one of the best predictive factors for learning outcomes [31, 32]. The previous research results confirmed the causal relationship of self-efficacy towards mathematics achievement supported by Mundia, and Metussin [33], Pitsia et al. [19], who revealed that self-efficacy had an influence on mathematics achievement in the $7^{\text {th }}$-grade and the $9^{\text {th }}$-grade students. Significantly, self-efficacy does not have only a direct influence with the confirmation of Mundia, and Metussin [33], Prast et al. [10], Tosco et al. [34], Rastegar et al. [35] and Habóka et al. [36], presented that self-efficacy plays a role as a mediator between the causal variables which affect the learning achievement, for example, the basic knowledge on mathematics achievement, an environment affecting mathematics learning results or interests in mathematics influencing mathematics learning results, etc.

Mathematics Aptitude is the ability or individual expertise about a particular subject that occurred after learning content from both formal and informal processes with the specified time frame. Students need to apply innate personal abilities to cope with learning situations [15]. It helps to explore learning to be easy and accomplished [12]. Mostly, aptitude has a positive relationship with motivation because when people do what they are good at, it inevitably causes the result with the desired direction [34]. Based on the research review, it was found that the researchers considered using aptitude as a predictive variable in mathematics achievement rather limited when comparing to other factors. However, research with explicit explaination on the role of aptitude are found, for example, Kriegbaum et al. [12] conducted a longitudinal study as the 4 waves between aptitude, motivation, and mathematics achievement of the $7^{\text {th }}$ grade students in order to consider the reciprocal effects of these three variables, aptitude, motivation, and mathematics. Each factor had a significant positive influence on each other with the statistical significance for the last measurement scores.

\subsection{Growth Mindset}

The implicit theories defining to describe beliefs about individual success are divided into 2 theories: Incremental Theory; the basis of the belief with individual intelligence and abilities through sufficient effort. In other words, it can be called a growth mindset, while Entity Theory believes that individual intelligence and abilities transfer to an individual and cannot change. We also know it as a fixed mindset [37, 38]. People with the growth mindset belief tend to have the learning flexibility, set clear goals, have a powerful motivation in learning, and explore ways to develop oneself. They do not have a fear of obstacles and failures in order to be proficient enough to achieve the success goals they set. On the other hand, fixed mindset believers tend to lack motivation for self-development and they tend to set performance goals by avoiding situations, encountering failures, and choosing situations appropriate for abilities and aptitude [39, 40]. Scholars and researchers have attempted to clarify the link between the different beliefs of the mindset and the learning outcomes from the 1980 s to the present. A growth mindset is a trait that promotes self-development in many aspects: cognitive, emotional, and behavioral engagement [41].

Referring to the cognitive domain, the significant findings revealed that growth mindset has the causal relationship with various learning outcomes, such as mathematics, science $[42,38,4,43]$, reading and writing abilities [41, 44], statistics [45], and pharmacy [46] by being able to develop the growth mindset of students with feedback provision [47, 44], educational game application [48, 49], and workshop application [50]. Furthermore, Liu et al. [51] found that the growth mindset is the most important factor in studying the students' academic performance.

As the aspect of emotional and behavioral engagement, it is the issue that has been extensively researched by Huang et al. [4], and Jach et al. [52]. They found that the growth mindset resulted in junior high school students to be interested in learning mathematics, leading to self-esteem, mathematics self-regulation. Later, it helps the students to relieve anxiety in mathematical learning. In addition, Mrazek et al. [53] Puente-Díaz and Cavazos-Arroyo [5] and McClendon [47] found out that the students with a growth mindset have not only the concise grit and self-regulation, but they also have a tendency to show good academic performance as lifelong learning, and have lower fatigue than fix mindset students, while Burgoyne et al. [54] Ng [55] and Rhew et al. [6] showed that the growth mindset correlated with grit affects locus of control and motivation of students.

Moreover, interesting findings revealed that learners with growth mindset play an important role in developing good citizenship by Waithaka et al. [56], Cooley and Larson [46], Nolder and Kadous [57], and Zander et al. [58] pointed out that students with a growth mindset have a clear tendency towards learning attitude, appreciation of learning, and happiness in various learning. Caniëls et al. [59], and Han et al. [39] revealed that a growth mindset has a tendency to stimulate the students with an awareness of maintaining public interest, having a public mind, and being volunteer activities for society. Besides, Jenkins et al. [60], Hermes and Rimanoczy [61] stated that the students with the growth mindset often have leadership qualities.

\subsection{Mediating Effect of Growth Mindset}

In the term of a mediator or mediating variable means three variables intervening in a causal relationship between an independent variable and a dependent variable. It affects the influence of the independent variable on the dependent variable $[62,63]$. It is applied to describe the relationship of the growth mindset as a mediator in the past 2010s. The findings make it possible to believe that a growth mindset 
has become one of the key factors affecting academic outcomes, behavioral expression, and contributes to explaining the causal relationship of other factors. Previous studies conducted by Cho et al. [41] showed that a growth mindset influences the mediators as cognitive, behavioral, and emotional engagement to reading comprehension, and the most are emotional influence, while fixed mindset has a negative influence on the reading comprehension of undergraduate students. According to Zander et al. [58], they found that self-efficacy influences the academic support network, with growth mindset acting as a mediator among college students, while Wang et al. [64] indicated that growth mindset acted as a mediator between the brain mechanisms towards grit of late adolescents. Moreover, Haimovitz et al. [65] also revealed that intrinsic motivation for self-development, achievement-ability is a mediator between entity theory of Intelligence on students' status as a decliner or maintainer of the $3^{\text {rd }}$ to $8^{\text {th }}$-grade students.

Referring to the nonacademic character, Orvidas et al. [66] pointed out that growth mindset influences the increased frequency of exercise and transmits influence through appreciation of exercise and perceptions of exercise among undergraduates. In addition, Tang et al. [67] revealed that the characteristics of college students in German and Poland who are aware of social coherence (called Horizontal) tend to be a mediator on growth mindset. However, when the students with the characteristics of independent tendency pay attention to oneself and family (called Vertical) is likely to be a mediator on fixed mindset. Yeager and Dweck [40] explained that according to the conflict between friends, growth mindset people have the opportunity to handle and manage the situations with great flexibility, as a result the problems can be resolved

Although there is evidence that growth mindset is a significant factor for mathematical achievement and has a role as a mediator for the desired cognitive and behavioral outcomes of students, it still lacks sufficient knowledge to prove and provide details about the mediating effect of the growth mindset, together with a group of variables. This group can clearly explain the variance of previously studied mathematical achievement. The researcher has the research question that how the growth mindset plays a role as a mediator in the causal's structure relationship between the factors' group influencing mathematics achievement and which of the causal factors have a common influence on mathematical achievement.

\section{Materials and Methods}

\subsection{Research Goal}

The goal of this research is a study of change in the model analysis of factors that influence mathematics achievement between a model without a growth mindset (Model A) and a growth mindset as a mediator (Model B).
However, the specified Model A relies on five cause variables including background knowledge (BACKG), attitude toward mathematics, mathematics self-efficacy, achievement motivation, and mathematics aptitude. It is believed that 1) achievement motivation (ACMOT) is influenced by mathematics aptitude, mathematics self-efficacy, attitude toward mathematics and background knowledge, 2) mathematics aptitude (MAPT) is influenced by mathematics self-efficacy, attitude toward mathematics, background knowledge, 3) mathematics self-efficacy (MEFF) is influenced by attitude toward mathematics and background knowledge, and 4) attitude toward mathematics (ATTIT) is influenced by background knowledge. As Model B, the structure is the same, but increasing the growth mindset (GROWTH) is influenced by all 5 cause variables and has a direct effect on mathematical achievement at the same time. Since various studies have shown that students with growth mindset tend to have better results than students with fix mindset, so the researcher used growth mindset scores of all subjects for the analysis of the influence without using fix mindset scores to participate in the analysis in Model B. Details of the Model A and Model B hypotheses are shown in Figure 1 and Figure 2.

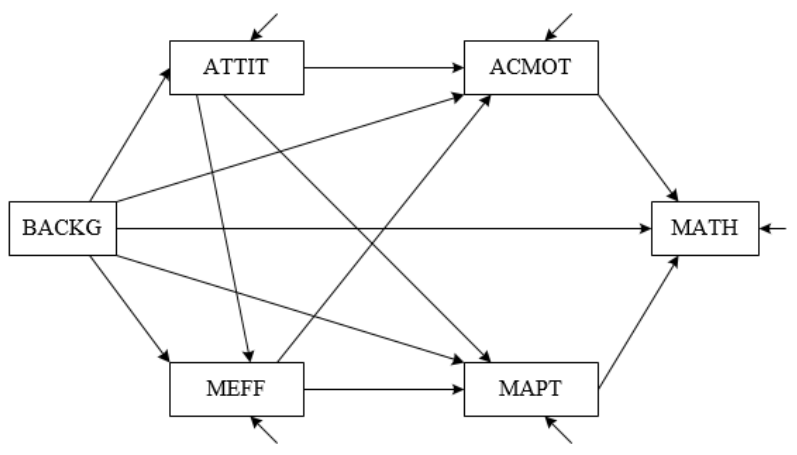

Figure 1. Model A

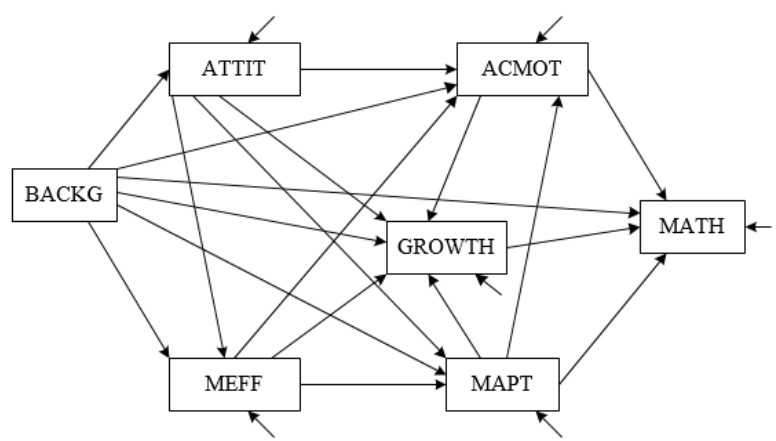

Figure 2. Model B

\subsection{Sample and Data Collection}

The research sample was 514 students, classified into 142 males $(27.60 \%$ ) and 372 females $(72.40 \%$ ) based on authentic gender proportion of population in the area, 
obtained from multistage random sampling from 6,989 of $9^{\text {th }}$ grade students in schools under the Secondary Educational Service Area Office 34, covering 76 schools. The important reason of determining samples as the $9^{\text {th }}$ grade students is for clarifying the influence of independent variables on mathematics learning outcomes in a population with significant learning differences in Thailand. The sample was set at "10 times on the number of parameters in the hypothesis model" [68], which has 31 values. Therefore, there should be a minimum sample number of 310 persons after data collection compiled with information raised for the classroom. It was found that data obtained from students had more than the minimum estimate. The sample consisted of 53 students in small size schools, 191 students in medium size schools, 94 students in large size schools, and 176 students in large special schools, respectively.

Research tools included: 1) Growth Mindset (GROWTH) which refers to beliefs in one's characteristics and others that can be developed or changed in terms of intelligence, personality, and characteristics in the desired direction with sufficient effort. It can be measured by 10 questions with 4 rating scales and it is interpreted with the tool of Diehl [69] which is adapted from Dweck [70]. There are 2 aspects in 7 questions for ability (for example, I can change my intelligence, If I work hard enough for something, it will be better) and 3 questions for personality/character aspects (such as Regardless of who we were in the past, we will always be able to change, I can change my original self). The discrimination index was between 0.304 to 0.606 and the reliability was $0.783,2)$ Achievement Motivation (ACMOT) means the desire to achieve or to succeed, not to discourage because of obstacles, and dare to face challenging problems. There were 15 questions for 5 rating scales (for example, I have never given up my intention when I decided what my goals were or I was happy to ask teachers to ask for errors and know the correct solution from the teachers. The discrimination index was between 0.350 to 0.694 and the reliability was $0.703,3$ ) Attitude toward Mathematics (ATTIT) means the feelings and behavior of students that recognize the benefits and values of learning mathematics, have an awareness and love for learning and behaviors in response to mathematical learning all the time. It can be measured by 10 questions with 5 rating scales (for example, I think math learning can be useful in everyday life or I have a lot of preparation for studying when studying mathematics). The discrimination index was between 0.448 to 0.740 and the reliability was $0.713,4$ ) Mathematics Self-efficacy (MEFF) refers to beliefs in one's own ability to succeed in learning and solving problems in mathematics. It can be measured by 15 questions with 5 rating scales (For example, I can always solve math-related problems or I often get scores in mathematics according to my set goals.) The discrimination index was between 0.315 to 0.618 and the reliability was $0.656,5)$ Background Knowledge (BACKG) is information, knowledge, understanding as well as experience gained from learning in mathematics. In this research, the data was collected from the mathematics grade point average (GPA) of the students when they studied in the $7^{\text {th }}-8^{\text {th }}$ grade, 6 ) Mathematics Achievement (MATH) is the result of the mathematics exam (Mathematics Ordinary National Education Test) of every $9^{\text {th }}$ grade student in Thailand. The test is conducted every year with a full score of 100 points. In this research, the MATH examination data were collected from the sample group from the score form which was notified back to students and schools, and 7) Mathematics Aptitude (MAPT) means competency or proficiency in numerical, reasoning, verbal and relational dimensions. It can be measured from 40 questions with 4 choices tests. The difficulty index was between 0.190 to 0.810 , the discrimination index was between 0.250 to 0.850 and the reliability (KR20) was 0.890 .

All 50 questions [collecting variable data from 1) to 6)] were collected in a set of questionnaires, then the students answered without the time limitation, and a set of Scholastic Aptitude Test (90 minutes of testing), tested within 2 weeks. the samples were provided the questionnaire's information, and spent 2 months for collection. There were 533questionnaires received (return rate was at 91.11\%); however, after checking the completeness and sincerity in the response, there were 514 questionnaires that could be the data for the research.

\subsection{Analyzing of Data}

The data were analyzed by descriptive statistics in order to study sociodemographic variables, and to consider the distribution of data for each variable, both skewness (sk) and kurtosis (kur), which should be valued between \pm 2 . Therefore, the inference showed that it has normality distribution [71] and correlation analysis. For assessing the degree of relationship between variables in a data set for determining multicollinearity problem together with consideration the variance inflation factor (VIF) should be no more than 10 and the tolerance statistics should be greater than 0.10 [72]. Then, proceed with the analysis of the data in response to the research objectives, starting with step 1, the analysis to check the validity of the model factors influencing MATH without growth mindset in the model (called Model A), step 2 , analysis to verify the validity of the model factors that influence MATH, with GROWTH in the model as a mediator (called Model B), the criterion for the consistency of the two hypothesis models with the empirical data was determined by the proportion of Chi-square value per degree of freedom (df), which should not be greater than 5 [73]. Comparative Fit Index (CFI) and Tucker-Lewis Index (TLI) should be greater than 0.900, Root Mean Square Error of Approximation (RMSEA) should be less than 0.06 [74, 75] using estimator as Maximum likelihood and also using 95\% bias-corrected bootstrap confidence interval based on 5,000 samples to analyze total effect, conditional indirect, and direct effect, 
step 3, mediation analysis to consider interaction with 3 independent variables in conjunction with GROWTH in each path as path $1(\mathrm{P} 1)$ : the mediating effect of growth mindset between ACMOT on MATH, path 2 (P2): the mediating effect of growth mindset between MAPT on $\mathrm{MATH}$, and path $3(\mathrm{P} 3)$ : the mediating effect of growth mindset between BACKG on MATH. The main principle in the analysis was applied from the simple mediation analysis. The consideration took place based on the change of direct effect of the independent variable $(\mathrm{X})$ towards the dependent variable $(\mathrm{Y})$ led to the effect onc between before and after increasing mediator ( $\mathrm{z}$ ) to analysis. Consequently, the independent variable $(\mathrm{x})$ affecting mediator $(\mathrm{z})$ led to the effect on a linked to a mediator (Z) which influenced the dependent variable $(y)$ and gained the effect of $b$. If it was found that the direct influence between before (c) and after (c ') increased, the mediator was decreased and not statistically significant. It showed that the growth mindset played a role of completely or full mediation. There was also a statistically significant decrease in straightness, indicating that growth mindset played a role in partial mediator $[76,77,78,63]$ by the analysis of the path analysis using Mplus 7.4.

\section{Findings / Results}

\subsection{Descriptive Statistics and Correlation Analysis}

The preliminary data found that the sample group of 514 students could be classified into 381 growth mindset students and 133 fix mindset students. It shows the details of the descriptive statistics of variables between the two groups in Appendix 1. The distribution of data has a normal curve. Each variable has a Sk value between -0.469 to 0.792 and a Kur value between -0.333 to -0.037 which is at both acceptable levels. Besides, 21 values of Pearson's $r$ in the correlation coefficient matrix represent values between 0.354 to 0.852 and there is a statistically significant difference at the level of 0.01 in every detail as in the table.

As the overall value, these values are at the medium to high level of relationship between variables. Moreover, the tolerance index is between 0.360 to 0.653 and the VIF is between 1.532 to 2.775 , which shows that the variables in the model are unlikely to cause multicollinearity problems.

\subsection{Model Fit Information}

The path analysis results between Model A and Model B are shown in Table 1. It is found that Model A shows the consistency index and empirical data. The index value is equal to $\chi 2=4.086, \mathrm{df}=2, \mathrm{p}$-value $=0.129$, RMSEA $=0.045$, $\mathrm{CFI}=0.999$, TLI=0.993. All effects in the model are significantly different from zero in the positive direction at the level of 0.05 and it can describe the variance of MATH in Model A as 79.9\%. In the other hand, Model B consists of $\chi 2=0.049, \mathrm{df}=2, \mathrm{p}$-value $=0.976, \mathrm{RMSEA}=0.000, \mathrm{CFI}=1.000$, TLI=1.008. All effects in the model are significantly different from zero in the positive direction at the level of 0.05 , except for the direct effect of ATTIT on the growth mindset. It can be explained that the variance of MATH in Model B was as $82.90 \%$, indicating that Model B was able to describe the relational structure of variables, or was more consistent with empirical data than Model A. Both models had differences into two parts: 1) the result of estimation of the direct effect of independent variables on MATH which is different as a result of the increase of mediator via growth mindset, and 2) there is the result of estimation of the direct effect of each variable on growth mindset. Therefore, it will interpret the factors that have effects on MATH from Model B because it is the model that is in harmony with the best empirical data and has the variables based on the conceptual framework completely.

As for the estimation of effects, it is found that the effect of Model A differs from the effect of Model B, only the direct effect of the factors that affect MATH, but the effect of the factors that influence the ACMOT, ATTIT, MEFF, and MAPT, including the R-square, is equal in all respects.

From Model B, the variables with the most direct effect on MATH is MAPT $(\beta=0.504 * *)$, followed by the GROWTH $\left(\beta=0.259^{* *}\right)$, BACKG $(\beta=0.218 * *)$, and ACMOT $\left(\beta=0.085^{* *}\right)$, respectively. The variables with the indirect effect on MATH the most are BACKG $(\beta=0.447 * *)$, ATTIT $(\beta=0.361 *)$, MEFF $(\beta=0.309 * *)$, respectively. The variables with the total effects on MATH the most are BACKG $(\beta=0.447 * *)$, MEFF $(\beta=0.616 * *)$, and ATTIT $(\beta=0.361 * *)$, respectively. Moreover, it is found that most of the factors deliver the direct effects GROWTH and MAPT is the factor having the effects GROWTH the most $(\beta=0.367 * *)$, followed by MEFF $\left(\beta=0.211^{* * *}\right)$ and $\operatorname{ACMOT~}(\beta=0.131 * *)$, respectively. Only ATTIT is not statistically significant.

According to the relationship between the important predictor variables revealed that ATTIT has the most effect on ACMOT and MEFF $(\beta=0.426 * *$ and $0.570 * *)$. BACKG has a positive effect on ATTIT $(\beta=0.354 * *)$ and MAPT has an effect on MEFF the most $\left(\beta=0.355^{* *}\right)$. Details of the effects between the variables are shown in Table 2. and Figure 3.

\subsection{Mediation Role of Growth Mindset}

The analysis results of Model B's growth mindset which was separately analyzed each path found that the model's consistency index and the empirical data are less than the results of the Model B analysis. The mediation effect analysis of the P2 path, with MAPT as independent variable was the model that had the best consistency index with the empirical data. The values are $\chi^{2} / \mathrm{df}=7.765$, p-value $=0.000, \quad$ RMSEA $=0.115, \quad$ CFI $/$ TLI $=0.999 / 0.946$. It shows that the use of all three independent variables to explain GROWTH variance has more effect on the harmonization of the model of the hypothesis with empirical data than using only one independent variable. 
Moreover, to consider the analysis of the mediating effect of GROWTH in each path, it revealed that 1) P1 Path considered ACMOT towards MATH through GROWTH and had the effect values as path $a=0.064, b=0.271$ and $c^{\prime}=0.089 *$. c' value decreases from $c$ in Model A (c-c' $=0.154-0.089$ ) as 0.065 and has the indirect effect value as $0.071(\mathrm{a} * \mathrm{~b}=0.264 * 0.271=0.071)$ (as in Figure $3 \mathrm{~A}$ ), 2) P2 path considers MAPT on MATH through GROWTH and gain the effect value as path $\mathrm{a}=0.459, \mathrm{~b}=0.261$ and $\mathrm{c}^{\prime}=0.508^{*}$. c' value changes to decrease from $\mathrm{c}$ in Model A equal to
0.109 and has the indirect effects as 0.120 (as in Figure 3B), and 3) P3 path determines BACKG towards MATH through GROWTH to obtain path effect as $\mathrm{a}=0.292, \mathrm{~b}=0.266$ and $c^{\prime}=0.224 *$ where $c^{\prime}$ decreased from $\mathrm{c}$ in model A of 0.040 and was charged with the indirect effect of 0.078 (as in Figure 3C). Therefore, it can be concluded that GROWTH has reduced direct effect and is still statistically significant at the level of 0.01 so that it has partial mediation in the model as detailed in Table 3 and Figure 3.

Table 1. Descriptive statistics and correlation matrix of all variables $(\mathrm{n}=514)$

\begin{tabular}{|c|c|c|c|c|c|c|c|}
\hline Variables & MATH & MAPT & MEFF & ACMOT & ATTIT & $\mathrm{BACKG}$ & GROWTH \\
\hline MATH & 1.000 & & & & & & \\
\hline MAPT & $0.852^{* *}$ & 1.000 & & & & & \\
\hline MEFF & $0.637^{* *}$ & $0.625^{* *}$ & 1.000 & & & & \\
\hline ACMOT & $0.636^{* *}$ & $0.598^{* *}$ & $0.701^{* *}$ & 1.000 & & & \\
\hline ATTIT & $0.553^{* *}$ & $0.541^{* *}$ & $0.660^{*}$ & $0.725^{* *}$ & 1.000 & & \\
\hline BACKG & $0.665^{\circ *}$ & $0.543^{* *}$ & $0.447^{+* *}$ & $0.431^{\text {** }}$ & $0.354^{* *}$ & 1.000 & \\
\hline GROWTH & $0.774^{* *}$ & $0.691^{* *}$ & $0.636^{* *}$ & $0.603^{* *}$ & $0.538^{* *}$ & $0.528^{* *}$ & 1.000 \\
\hline Mean & 42.642 & 0.488 & 3.846 & 3.796 & 3.762 & 3.039 & 2.133 \\
\hline $\mathrm{SD}$ & 20.834 & 0.188 & 0.415 & 0.437 & 0.437 & 0.743 & 0.533 \\
\hline SK & 0.704 & 0.792 & -0.017 & 0.089 & -0.040 & -0.469 & -0.364 \\
\hline KUR & -0.333 & -0.037 & -0.171 & -0.169 & -0.128 & -0.528 & -0.457 \\
\hline Tolerance & & 0.422 & 0.391 & 0.360 & 0.423 & 0.653 & 0.422 \\
\hline $\mathrm{VIF}<10$ & & 2.370 & 2.557 & 2.775 & 2.363 & 1.532 & 2.369 \\
\hline
\end{tabular}

Note: 1) MATH=Mathematics Achievement, MAPT=Mathematics Aptitude, MEFF=Mathematics Self-efficacy, ACMOT=Achievement Motivation, ATTIT=Attitude toward Mathematics, BACKG=Mathematical Background Knowledge, GROWTH=Growth Mindset 2) $* *$ p $<0.01$

Table 2. Analysis Results of Standardized Direct Effects of Variable Structure of the Models

\begin{tabular}{|c|c|c|c|c|c|c|c|c|c|}
\hline \multirow{2}{*}{ DV } & \multirow{2}{*}{ IV } & \multicolumn{4}{|c|}{ MODEL A } & \multicolumn{4}{|c|}{ MODEL B } \\
\hline & & $\beta$ & SE & $95 \%$ CI & $\mathrm{R}^{2}$ & $\beta$ & SE & $95 \% \mathrm{CI}$ & $\mathrm{R}^{2}$ \\
\hline \multirow[t]{4}{*}{ MATH } & ACMOT & 0.154 & 0.026 & $(0.103-0.205)$ & \multirow{4}{*}{0.799} & 0.085 & 1.179 & $(0.036-0.134)$ & \multirow{4}{*}{0.829} \\
\hline & MAPT & 0.617 & 0.027 & (0.564-0.669) & & 0.504 & 3.262 & $(0.447-0.561)$ & \\
\hline & BACKG & 0.264 & 0.028 & $(0.210-0.318)$ & & 0.218 & 0.760 & (0.167-0.269) & \\
\hline & GROWTH & - & - & - & & 0.259 & 9.105 & $(0.203-0.315)$ & \\
\hline \multirow[t]{4}{*}{ ACMOT } & ATTIT & 0.426 & 1.230 & $(0.343-0.509)$ & \multirow{4}{*}{0.634} & 0.426 & 0.044 & $(0.343-0.509)$ & \multirow{4}{*}{0.634} \\
\hline & MEFF & 0.300 & 0.050 & $(0.208-0.393)$ & & 0.300 & 0.051 & $(0.208-0.393)$ & \\
\hline & MAPT & 0.142 & 0.094 & $(0.062-0.222)$ & & 0.142 & 0.094 & $(0.062-0.222)$ & \\
\hline & $\mathrm{BACKG}$ & 0.069 & 0.020 & $(0.003-0.135)$ & & 0.069 & 0.020 & $(0.003-0.135)$ & \\
\hline ATTIT & BACKG & 0.354 & 0.025 & $(0.282-0.426)$ & 0.125 & 0.354 & 0.025 & $(0.282-0.426)$ & 0.125 \\
\hline \multirow[t]{2}{*}{ SCON } & BACKG & 0.244 & 0.018 & $(0.183-0.304)$ & \multirow{2}{*}{0.488} & 0.244 & 0.018 & (0.183-0.304) & \multirow{2}{*}{0.488} \\
\hline & ATTIT & 0.574 & 0.035 & $(0.511-0.637)$ & & 0.574 & 0.035 & $(0.511-0.637)$ & \\
\hline \multirow[t]{3}{*}{ MAPT } & BACKG & 0.315 & 8.974 & $(0.250-0.380)$ & \multirow{3}{*}{0.499} & 0.315 & 0.009 & $(0.250-0.380)$ & \multirow{3}{*}{0.499} \\
\hline & ATTIT & 0.195 & 0.017 & $(0.119-0.272)$ & & 0.195 & 0.017 & $(0.119-0.272)$ & \\
\hline & MEFF & 0.355 & 0.020 & $(0.274-0.437)$ & & 0.355 & 0.020 & $(0.274-0.437)$ & \\
\hline \multirow[t]{5}{*}{ GROWTH } & BACKG & & & & & 0.161 & 0.028 & $(0.087-0.236)$ & \multirow{5}{*}{0.578} \\
\hline & ATTIT & & & & & 0.041 & 0.050 & $(-0.032-0.126)$ & \\
\hline & MEFF & & & & & 0.211 & 0.061 & $(0.122-0.301)$ & \\
\hline & MAPT & & & & & 0.367 & 0.117 & $(0.288-0.447)$ & \\
\hline & ACMOT & & & & & 0.131 & 0.057 & $(0.040-0.223)$ & \\
\hline \multicolumn{2}{|c|}{ Model Fit Indices } & \multicolumn{4}{|c|}{$\begin{array}{c}\chi 2=4.086, \mathrm{df}=2, \mathrm{p}-\text { value }=0.129, \text { RMSEA }=0.045 \\
\text { CFI }=0.999, \text { TLI }=0.993\end{array}$} & \multicolumn{4}{|c|}{$\begin{array}{c}\chi 2=0.049, \mathrm{df}=2, \mathrm{p}-\mathrm{value}=0.976, \text { RMSEA }=0.000 \\
\text { CFI }=1.000, \text { TLI }=1.008\end{array}$} \\
\hline
\end{tabular}

Note: 1 ) MATH=Mathematics Achievement, MAPT=Mathematics Aptitude, MEFF=Mathematics Self-efficacy, ACMOT=Achievement Motivation, ATTIT $=$ Attitude toward Mathematics, BACKG=Mathematical Background Knowledge, GROWTH=Growth Mindset 2) Model A has no growth mindset as a mediator in the model 3) Model B has a variable as growth mindset to be as mediator cooperated from ACMOT, MAPT, BACKG. 
Table 3. The Analysis Results of Mediating Effect through Growth Mindset

\begin{tabular}{cccc}
\hline Path & P1. & P2. & P3. \\
\hline a: $X \rightarrow Z$ & ACMOT $\rightarrow$ GROWTH $\rightarrow$ MATH & MAPT $\rightarrow$ GROWTH $\rightarrow$ MATH & BACKG $\rightarrow$ GROWTH $\rightarrow$ MATH \\
b: $\mathrm{Z} \rightarrow \mathrm{Y}$ & $0.264^{* *}$ & $0.459^{* *}$ & $0.292^{* *}$ \\
$\mathrm{c}: \mathrm{X} \rightarrow \mathrm{Y}$ & $0.271^{* *}$ & $0.261^{* *}$ & $0.266^{* *}$ \\
$\mathrm{c}^{*}: \mathrm{X} \rightarrow \mathrm{Y}$ & $0.154^{* *}$ & $0.617^{* *}$ & $0.264^{* *}$ \\
\hline Fit Index & $0.089^{* *}$ & $0.508^{* *}$ & $0.224^{* *}$ \\
\hline$\chi^{2}$ /df & & & $90.167 / 4=22.542$ \\
p-value & $130.285 / 4=32.571$ & $31.058 / 4=7.765$ & 0.000 \\
RMSEA & 0.000 & 0.000 & 0.205 \\
CFITLI & 0.248 & 0.115 & $0.967 / 0.827$ \\
\hline
\end{tabular}

Note: 1) MATH=Mathematics Achievement, ACMOT=Achievement Motivation, MAPT=Mathematics Aptitude, BACKG=Mathematical Background Knowledge, GROWTH=Growth Mindset 2) ATTIT and MEFF variables do not have a direct effect on MATH in the hypothesis model; 3)** $<<0.01 ; 4$ ) a represents the effect of factors on growth mindset 5) b represents the effect of growth mindset on MATH; 6) c represents the direct effect of factors on MATH; 7) $\mathrm{c}$ * represents the direct effect of factors on MATH when controlled by growth mindset as a mediator

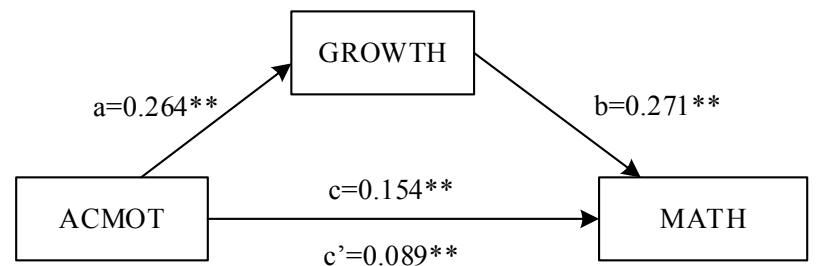

$(3 \mathrm{~A})$

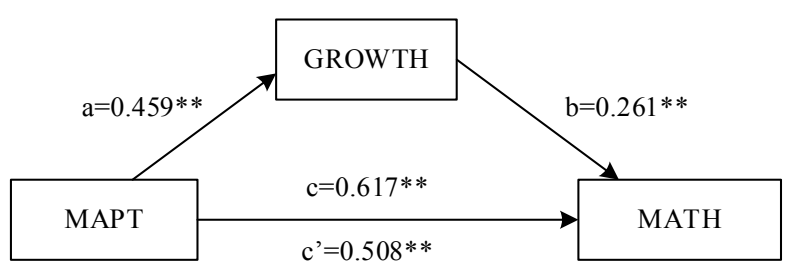

(3B)

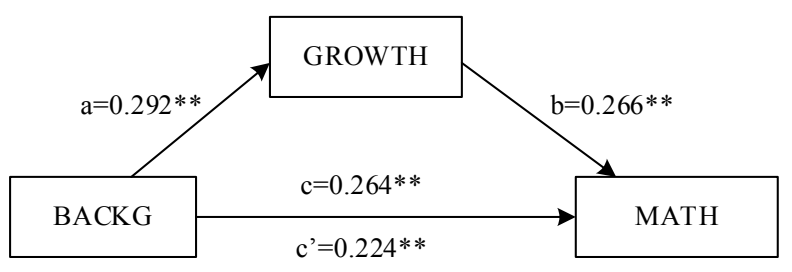

(3C)

Note: 1) MATH=Mathematics Achievement, MAPT=Mathematics Aptitude, ACMOT=Achievement Motivation, BACKG=Mathematical Background Knowledge, GROWTH=Growth Mindset 2) ${ }^{* *} \mathrm{p}<0.01$

Figure 3. Mediation effects of growth mindset

\section{Conclusion and Discussion}

The significant findings can be concluded that the growth mindset is a variable playing a significant role in all variables in the model distinctively. The researcher has 3 discussion points about the findings:

First, the comparison of factors model influencing the MATH between model A and model B shows that the model that links the relationship of each factor with the growth mindset, including path analysis separately still confirms that Model B is perfectly consistent with the empirical data. Importantly, it presents that growth mindset is the significant factor for the variable structure in the model according to incremental theory [79] and it describes the characteristics of growth mindset as a response to internal development, attempt to apply thought for encountering obstacles and looking at obstacles as lessons to develop new abilities. The students with growth mindset characteristics will have the view that teachers are essential learning resources. It increases the chances of personal development, courage to face challenges and be free from the fear of mistakes as a lesson for better learning. On the contrary, the students with a fix mindset tend to be more aware of proving their abilities in various situations, have an awareness of interaction with others in the form of being watched. Therefore, they are prudent of the consequences of actions that cause problems and failures. Consequently, it is not surprising that the causes of all variables in the model have a causal relationship in the positive direction with the whole growth mindset, and adding the growth mindset as part of the model will increase the clarification of the model's assumptions with the consistency of more realistic phenomenon. It can be concluded that the results of this research still confirm the causal relationship of previous findings, such as growth mindset was found to influence learning motivation, able to cope better with learning anxiety [46, 57], have learning motivation [80, 81, 5], recognize the ability to manage and solve problems [39, 6], have good self-planning and self-control [82, 83] as well as have effective lifelong learning abilities [48, 56]. The above reasons support that causal structure between variables is based on the research hypothesis.

Second, although the findings from the research provide information on the number of paths of various effects, it most likely has indirect effects significantly different from zero in a positive direction. But if considering the implication, only prominent interesting paths, the researcher found that BACKG has an effect on all variables 
in the model due to the evident effect for direct, indirect and total effects, especially MAPT, which found that BACKG $\rightarrow$ MAPT $\rightarrow$ MATH obtains $\beta=0.159$ but BACKG is not an important variable to ACMOT. Considering BACKG $\rightarrow$ ACMOT's effect, it is at the low level and ACMOT $\rightarrow$ MATH is also the same. The indirect effect does not differ from zero $(\beta=0.006)$, indicating that ACMOT does not have a good interaction to explain MATH. ATTIT becomes the most important variable that affects ACMOT, showing that the mathematical background knowledge plays a vital role in the development of important learning features, specifically helping to strengthen basic math skills, and bring to the desired mathematical results while ATTIT will play a major role in the development of ACMOT and lead to better mathematical results. It is consistent with Kriegbaum et al. [12] who conducted longitudinal research, found that the background knowledge taught by teachers has a reciprocal effect on students' aptitude, and leads to mathematical learning results and the findings also revealed that intrinsic motivation is not an important factor in describing mathematical learning results of $7^{\text {th }}$ grade students.

ATTIT is another factor that plays an important role in other factors. Overall, ATTIT has no effect on MATH via the growth mindset. The indirect effect has no difference from zero but will begin to see the indirect effect clearly when considering the indirect effect of growth mindset with other factors, especially ATTIT $\rightarrow$ SEFF $\rightarrow$ MAPT $\rightarrow$ MATH $\quad=0.103$ and ATTIT $\rightarrow$ MAPT $\rightarrow$ MATH $=0.098$, in line with previous research [84, 12, 19, 35] that have found a common relationship of attitude toward mathematics, self-efficacy, and learning aptitude on mathematics learning outcome

ATTIT does not influence GROWTH. The researchers found that the indirect effect of ATTIT through GROWTH to MATH is not different from zero which does not correspond to Nolder and Kadous [57] and Cooley and Larson [46] who pointed out the connection of these two factors. This may be due to 1 ) the researcher specifies the conceptual framework for the study of ATTIT's results without the direct effect on MATH, and 2) the review of relevant literature is not sufficient to conclude the direct connection of ATTIT on MATH, which linked with the use of growth mindset as a mediator. However, ATTIT remains a clear relationship with other factors as described. Therefore, the researcher still considers ATTIT to be a prominent factor and should continue to study the characteristics and roles clearly for future clarity.

Third, the results indicated that the growth mindset interacts with a set of independent variables in the form of a partial mediation, in which each variable has indirect effect via growth mindset to MATH with statistical significance. It is consistent with Wang et al. [64] who found the partial mediation between the causal relationships of gray matter structure on grit in late adolescence. Zander et al. [58] also found that growth mindset (measured by self-perceived popularity academic support network) plays a role of partial mediation from the actual popularity academic support network that was first measured to the 2 nd measurement. It indicates that math learning results are caused by many factors from the students themselves (which is partly explained by the variable framework in the hypothesis model) friends group [85, 10,40], family [1, 8], teachers [20, 86,44 ] as well as the school context [34]. Therefore, there are still many factors beyond the conceptual framework of research that can explain the causal relationship and may have the role of a mediator as a growth mindset. It can also be used to clearly explain the difference of direct effect values if more complex effect characteristics are proven, such as moderated mediation, mediated moderation, and multiple mediation analysis, etc. [63, 87]. It is possible that if a statistical model is developed that can clearly explain and prove the relationships and roles of variables, it may find the roles of growth mindset more clearly.

Since this research is a quantitative research, it intends to prove the causal relationship between the variables unlike experimental research focusing on developing interventions and aims at changing the learning outcomes of learners, such as Limeri et al. [88] found that students with continuing struggle will have a tendency to develop towards Fixed Mindset traits, while students who are overcame struggle and never struggled tend to develop a high level of constant development in the manner of Growth Mindset through STEM education management Yeager et al. [89] found information from meta-analysis that Growth Mindset intervention reduced self-perception according to Fix Mindset traits and led to students' development of Mathematics, Science, English, and Social Studies GPA. Moreover, Dowdy [90] revealed that the development of mindset with the Khan Academy mindset intervention resulted in a more positive correlation between mathematics motivation and mathematics achievement. Aforementioned research and findings supported that growth mindset does not affect learning outcomes solely, but academic ability also affects the development of the mindset, so the development of mindset inevitably contributes to the learning success of the learners.

The conclusion of this research is in accordance with the objectives and research hypothesis. The hypothesis model can explain the relationship structure of variables according to the research framework very well. The mathematical background knowledge is a fundamental factor in describing the structure of the factors that affect the results of mathematics learning. While aptitude in learning is the most directly influencing factor in mathematics learning, the attitude towards learning and self-efficacy has a slightly less indirect effect than the mathematical background. Moreover, the growth mindset influences mathematical learning and plays a partial mediation role between mathematical background knowledge, motivation for achievement, and learning 
aptitude on mathematics learning outcomes of all 3 factors. All 6 factors explain mutually the variance of mathematics learning results by $83.90 \%$.

\section{Suggestions}

Based on this research, the researcher has 3 important suggestions for implementation: 1) teachers should have an awareness that the previous mathematical background knowledge is an important basis for the desired characteristics and results of mathematical learning. Establishing the necessary mathematical background clearly and precisely not only helps students develop their aptitude for learning to achieve mathematical learning results but also includes the emergence of learning characteristics that enhance learning more effectively, 2) Developing learners with growth mindset perception, teachers should design activities to develop their perceptions and develop learning aptitude. They may use an evaluation method with feedback reflection about strengths points and developing points. For example, research conducted by McClendon et al. [47], Smiht et al. [45], and Truax [44], or in the case of primary or secondary school students, may design activities to increase awareness through games to challenge in chronological level and provide students the opportunity to apply strategic design by themselves, such as the research by Gummesson and Remedios [48] and O'Rourke et al. [49], will greatly improve the development of mathematical learning capabilities with the tendency of more success, 3 ) As the development of learners or research studies to explain the causal relationship of factors influencing the results of mathematics learning in the future indicates that even though the results of this research confirm the relation of variable sets in the model closely, there are still some interesting variables. Moreover, they can be used to explain the phenomena in the learning context of learners more distinctly from the dimension of the family, the teachers, and the educational institutions, which enlighten the learners having awareness and belief in their abilities, both in growth and fix mindset differently.

\section{Acknowledgements}

The researcher would like to thank the teachers and students for providing research information. Thank Ms.Wassana Kajai for helping to collect research data and thank the Faculty of Education, Chiang Mai University that supports funding of this research.

\section{Appendix 1. Descriptive Statistics of Fix and Growth Mindset}

\begin{tabular}{|c|c|c|c|c|c|c|c|c|c|c|c|c|}
\hline \multirow{2}{*}{ Variables } & \multicolumn{6}{|c|}{ Fix Mindset $(n=133)$} & \multicolumn{6}{|c|}{ Growth Mindset (n=381) } \\
\hline & Min. & Max. & Mean & SD & Sk & Kur & Min. & Max. & Mean & SD & Sk & Kur \\
\hline BACKG & 1.000 & 4.000 & 2.553 & 0.666 & -0.149 & -0.483 & 1.460 & 4.000 & 3.208 & 0.692 & -0.690 & -0.164 \\
\hline ATTIT & 2.670 & 4.420 & 3.561 & 0.368 & -0.082 & -0.376 & 2.670 & 5.000 & 3.832 & 0.438 & -0.150 & -0.012 \\
\hline MEFF & 2.470 & 4.230 & 3.584 & 0.314 & -0.314 & 0.110 & 2.700 & 5.000 & 3.938 & 0.407 & -0.169 & -0.108 \\
\hline MAPT & 0.120 & 0.780 & 0.347 & 0.105 & 1.269 & 3.035 & 0.130 & 0.980 & 0.538 & 0.185 & 0.629 & -0.356 \\
\hline ACMOT & 2.300 & 4.500 & 3.546 & 0.360 & 0.052 & 0.661 & 2.600 & 5.000 & 3.884 & 0.428 & -0.002 & -0.241 \\
\hline MATH & 6.400 & 76.000 & 23.523 & 9.545 & 2.376 & 10.164 & 9.600 & 100.000 & 49.316 & 19.538 & 0.563 & -0.509 \\
\hline
\end{tabular}

Note: MATH=Mathematics Achievement, MAPT=Mathematics Aptitude, MEFF= Mathematics Self-efficacy, ACMOT=Achievement Motivation, ATTIT=Attitude toward Mathematics, BACKG=Mathematical Background Knowledge 


\section{REFERENCES}

[1] Dinkelmann I., Buff A. “Children's and Parents' Perceptions of Parental Support and Their Effects on Children's Achievement Motivation and Achievement in Mathematics: A Longitudinal Predictive Mediation Model," Learning and Individual Differences, vol. 50, pp. 112-132, 2016.

[2] Kiwanuka H. N., Damme J. V., Noortgate W. V. D., Anumendem D. N., Namusisi S. "Factors Affecting Mathematics Achievement of First-year Secondary School Students in Central Uganda," South African Journal of Education, vol.35, no. 3, pp. 1-16, 2015

[3] Bahník Š., Vranka M. A. "Growth mindset is not associated with scholastic aptitude in a large sample of university applicants," Personality and Individual Differences, vol. 117, pp. 139-143, 2017

[4] Huang X., Zhang J., Hudson L. "Impact of Math Self-Efficacy, Math Anxiety, and Growth Mindset on Math and Science Career Interest for Middle School Students: The Gender Moderating Effect," European Journal of Psychology of Education, 2018. DOI: 10.1007/s10212-018-0403-Z

[5] Puente-Díaz R., Cavazos-Arroyo J. "The Influence of Creative Mindsets on Achievement Goals, Enjoyment, Creative Self-Efficacy and Performance Among Business Students," Thinking Skills and Creativity, vol. 24, pp. 1-11, 2017.

[6] Rhew E., Piro J. S., Goolkasian P., Cosentino, P. “The Effects of a Growth Mindset on Self-Efficacy and Motivation," Curriculum \& Teaching Studies, vol. 5, pp. 1-16, 2017.

[7] Mayer R. E. "Memory and Information Process," in Handbook of Psychology. 7th ed, John Wiley \& Son, 2003, pp. $47-58$

[8] Froiland J. H., Davison M. L. "The Longitudinal Influences of Peers, Parents, Motivation, and Mathematics Course-Taking on High School Math Achievement," Learning and Individual Differences, vol. 50, pp. 252-259, 2016

[9] Putwain D. W., Symes W., Nichoson L. J., Becker S. "Achievement Goals, Behavioral Engagement, and Mathematics Achievement: A Mediational Analysis," Learning and Individual Differences, vol. 68, pp. 12-19, 2018.

[10] Prast E. J., Weijer-Bergsma E. V., Miočević M., Kroesbergen E. H., Van Luit J. E. H. "Relations between Mathematics Achievement and Motivation in Students of Diverse Achievement Levels," Contemporary Educational Psychology, vol. 55, pp. 84-96, 2018

[11] Soland, J. "Modeling Academic Achievement and Self-Efficacy as Joint Developmental Processes: Evidence for Education, Counseling, and Policy," Journal of Applied Developmental Psychology, vol. 65, 101076, 2019.

[12] Kriegbaum K., Steinmayr R., Spinath B. "Longitudinal Reciprocal Effects between Teachers' Judge Growth Mindsetents of Students' Aptitude, Students' Motivation, and Grades in Math," Contemporary Educational Psychology, vol. 59, 101807, 2019 .
[13] Ryan R. M., Deci E. L. "Relationships Motivation Theory: The Self in Close Relationships," in Self-determination Theory: Basic Psychological Needs in Motivation, Development, and Wellness. The Guilford Press, 2017, pp. 293-310.

[14] Duchesne S., McMaugh A. "Educational Psychology," 5th ed., Cengage Learning. 2018.

[15] Salkind, N. J. "Encyclopedia of Educational Psychology," Sage, 2008.

[16] Shaffer D. R., Kipp K. Developmental Psychology, Childhood and Adolescence, 8th ed., Wadsworth, 2010.

[17] Santrock J. W. Educational Psychology, 6th ed., McGraw Hill, 2018.

[18] Sriphai S., Damrongpanit S., Sakulku J. "An Investigation of Learning Styles Influencing Mathematics Achievement of Geventh-Grade Students," Educational Research and Reviews, vol. 6, no. 15, pp. 835-845, 2011.

[19] Pitsia V., Biggart A., Karakolidis A. "The Role of Students' Self-beliefs, Motivation and Attitudes in Predicting Mathematics Achievement: A Multilevel Analysis of the Programme for International Student Assessment Data," Learning and Individual Differences, vol. 55, pp. 163-173. 2017.

[20] Damrongpanit S. "From Modern Teaching to Mathematics Achievement: The Mediating Rrole of Mathematics Attitude, Achievement Motivation, and Self-Efficacy," European Journal of Educational Research, vol. 8, no. 3, pp. 713-727, 2019.

[21] Olson J. M., Maio G. R. "Attitudes in social behavior." in Handbook of Psychology, vol. 5, Personality and Social Psychology. John Wiley \& Son, 2003

[22] Ames C. A. "Motivation: what teachers need to know?" Teacher College Record, vol. 91, pp. 409-421, 1990.

[23] Elliot A. J., Covington M. V. "Approach and Avoidance Motivation," Educational Psychology Review, vol. 13, no. 2, pp. 73-92. 2001.

[24] Ma X., Kishor N. "Assessing the Relationship between Attitude toward Mathematics and Achievement in Mathematics: A Meta-Analysis," Journal for Research in Mathematics Education, vol. 28, no. 1, pp. 26-47, 1997.

[25] Kayacan K., Ektem I. S. "The Effects of Biology Laboratory Practices Supported with Self-Regulated Learning Strategies on Students' Self-Directed Learning Readiness and Their Attitudes towards Science Experiments," European Journal of Educational Research, vol. 8, no. 1, pp. 313-323, 2019.

[26] Yurdakal I. H. "Examination of Correlation between Attitude towards Reading and Perception of Creative Reading," European Journal of Educational Research, vol. 8, no. 2, pp. 443-452, 2019

[27] Gudek B. "Computer Self-Efficacy Perceptions of Music Teacher Candidates and Their Attitudes towards Digital Technology," European Journal of Educational Research, vol. 8, no. 3, pp. 683-695, 2019.

[28] Bentham S. “Psychology and Education,” Rutledge, 2002

[29] Bandura A. Social Foundations of Thought and Action: A 
Social Cognitive Theory," Prentice-Hall, 1986.

[30] Pintrich P. R. "Motivation and classroom learning," in Handbook of Psychology, Vol. 7, Educational Psychology. John Wiley \& Son, Inc., Hoboken, 2003.

[31] Bandura A. "Self-Efficacy: The Exercise of Control," Freeman, 1997.

[32] Schunk D. H. "Self-Efficacy and Academic Motivation," Educational Psychologist, vol. 26, pp. 207-231, 1991.

[33] Mundia L., Metussin H. "Exploring Factors that Improve Mathematics Achievement in Brunei," Studies in Educational Evaluation, vol. 60, pp. 214-222, 2019.

[34] Tosco M. G., Asbury K., Mazzocco M. M. M., Petrill S. A., Kovas Y. "From Classroom Environment to Mathematics Achievement: The Mediating Role of Self-Perceived Ability and Subject Interest," Learning and Individual Differences, vol. 50, pp. 260-269, 2016.

[35] Rastegar A., Jahromi R. G., Haghighi A. S., Akbari A. R. "The Relation of Epistemological Beliefs and Mathematics Achievement: The Mediating Role of Achievement Goals, Mathematics Self-Efficacy, and Cognitive Engagement," Procedia Social and Behavioral Sciences, vol. 5, pp. 791-797, 2010.

[36] Habóka A., Magyarb A., Németha M. B., Csapó B. "Motivation and Self-Related Beliefs as Predictors of Academic Achievement in Reading and Mathematics Structural Equation Models of Longitudinal Data," International Journal of Educational Research, 103, 101634, 2020 .

[37] Blackwell L., Trzesniewski K., Dweck C. S. "Implicit Theories of Intelligence Predict Achievement Across an Adolescent Transition: A Longitudinal Study and an Intervention," Child Development, vol. 78, pp. 246-263, 2007.

[38] Dweck C. S. "Mindsets and Math/Science Achievement." https:/www.growthmindsetmaths.com/uploads/2/3/7/7/23776 169/mindset and math science achievement_nov 2013. pdf (accessed May 19, 2008)

[39] Han H., Choi Y., Dawson K. J., Jeong C. "Moral Growth Mindset is Associated with Change in Voluntary Service Engagement," PLoS ONE, 2018. DOI: 10.1371/journal.pone.0202327

[40] Yeager D. S., Dweck C. S., "Mindsets that promote resilience: When students believe that personal characteristics can be developed," Educational Psychologist, vol. 47, no. 4, pp. 302-314. 2012

[41] Cho E., Toste J. R., Lee M., Ju U., "Motivational Predictors of Struggling Readers' Reading Comprehension: The Effects of Mindset, Achievement Goals, and Engagement," Reading and Writing, 2018. DOI: 10.1007/s11145-018-9908-8

[42] Boyd P., Ash A., "Mastery Mathematics: Changing Teacher Beliefs Around In-Class Grouping and Mindset," Teaching and Teacher Education, vol. 75, pp. 214-223, 2018.

[43] Willingham J. C. "Revealing Layered Mathematical Learning Goals Through an Examination of Mindset," The 39th annual meeting of the North American Chapter of the International Group for the Psychology of Mathematics Education, Indianapolis, IN: Hoosier Association of Mathematics Teacher Educators, 2017, pp. 1170-1177.
[44] Truax M. L. "The Impact of Teacher Language and Growth Mindset Feedback on Writing Motivation," Literacy Research and Instruction, 57Z2X, pp. 135-157, 2018.

[45] Smiht T., Brumskill R., Jhonson A., Zimmer T., “The Impact of Teacher Language on Students' Mindsets and Statistics Performance," Social Psychological Education, vol. 21, pp 775-786, 2018

[46] Cooley J. H., Larson S., "Promoting a Growth Mindset in Pharmacy Educators and Students," Currents in Pharmacy Teaching and Learning, vol. 10, pp. 675-679, 2018.

[47] McClendon C., Neugebauer R. M., King A., "Grit, Growth Mindset, and Deliberate Practice in Online Learning," Journal of Instructional Research, vol. 6, pp. 8-17, 2017

[48] Gummesson C., Remedios L. J., "Searching our Mindset Looking at Places and Spaces in Education," Physical Therapy Reviews, vol. 23, no. 1, pp. 1-3, 2018.

[49] O'Rourke E., Haimovitz K., Ballweber C., Dweck C. S., Popovi'C, Z. "Brain points: A growth mindset incentive structure boosts persistence in an educational game," The ACM CHI Conference on Human Factors in Computing Systems is the premier international conference of Human-Computer Interaction, Aug 2014, Toronto, Canada, pp. 3339-3348

[50] Hochanadel A., Finamore D., "Fixed and Growth Mindset in Education and How Grit Helps Students Persist in the Face of Adversity," Journal of International Education Research, vol. 11, no. 1, pp. 47-50, 2015.

[51] Liu Y., Robinson M. N., Xu H., "The Effect of Mindset on Students' Desire to Work for Big Four Accounting Firms and on Academic Performance," e-Journal of Business Education \& Scholarship of Teaching, vol. 12, no. 2, pp.91-106, 2018

[52] Jach H, K., Sun J., Loton D., Chin T., Waters L. E., "Strengths and Subjective Wellbeing in Adolescence: Strength-Based Parenting and the Moderating Effect of Mindset," Journal of Happiness Study, vol. 19, pp. 567-586, 2018

[53] Mrazek A. J., Ihm E. D., Molden D. C., Mrazek M. D., Zedelius C. M., Schooler J. W., "Expanding Minds: Growth Mindsets of Self-Regulation and the Influences on Effort and Perseverance," Journal of Experimental Social Psychology, vol. 79, pp. 164-180, 2018.

[54] Burgoyne A. P., Hambrick D. Z., Moser J. S., Burt A., "Analysis of a Mindset Intervention," Journal of Research in Personality, vol. 77, pp. 21-30, 2018

[55] Ng B. "The Neuroscience of Growth Mindset and Intrinsic Motivation,"Brain Sciences, vol. 8. no. 20, pp. 1-10, 2018.

[56] Waithaka A. G., Furniss T. M., Gitimu P. N. “College Student Mindset: Does Student-Parental Relationship Influence the Student's Mindset?" Research in Higher Education Journal, vol. 31, pp. 1-16, 2017.

[57] Nolder C. J., Kadous, K, "Grounding the Professional Skepticism Construct in Mindset and Attitude Theory: A Way Forward," Accounting, Organizations and Society, vol. 67 ,pp. $1-14,2018$

[58] Zander L., Brouwer J., Jansen E., Crayen C., Hannover, B., "Academic Self-Efficacy, Growth Mindsets, and University Students' Integration in Academic and Social Support Networks," Learning and Individual Differences, vol. 62, pp 
98-107. 2018.

[59] Caniëls M. C. J., Semeijn J. H., Renders I. H. M., "Mind the Mindset! The Interaction of Proactive Personality, Transformational Leadership and Growth Mindset for Engagement at Work," Career Development International, vol. 23, no. 1, pp. 48-66, 2018.

[60] Jenkins C, Harris E., Krumm B., Curry K., "Cultivating a Global Mindset in Leadership Preparation: Contextual Implications," Journal of International Education and Leadership, vol. 2, no. 3, pp. 1-17, 2012.

[61] Hermes J., Rimanoczy I., "Deep Learning for a Sustainability Mindset," The International Journal of Management Education, vol. 16, pp. 460-467, 2018.

[62] Chrong J. MacKinnon D. O., "Mediation/Indirect Effect in Structural Equation Modeling," in Handbook of Structural Equation Modeling, The Guilford Press, 2012, pp. 418.

[63] Hayes A. F. "Mediation, Moderation, and Conditional Process Analysis: A Regression-Based Approach," The Guilford Press, 2018, pp. 7.

[64] Wang S., Dai J., Li J., Chen T., Yang X., He M., Gong Q., "Neuroanatomical Correlates of Grit: Growth Mindset Mediates the Association between Gray Matter Structure and Trait Grit in Late Adolescence," Human Brain Mapping, vol.39, pp. 1688-1699, 2018.

[65] Haimovitz K., Wormington S. V., Corpus J. H., "Dangerous Mindsets: How Beliefs about Intelligence Predict Motivational Change," Learning and Individual Differences, vol. 21, pp. 747-752, 2011.

[66] Orvidas K., Burnette J. L., Russell V. M., "Mindsets Applied to Fitness: Growth Beliefs Predict Exercise Efficacy, Value and Frequency," Psychology of Sport \& Exercise, vol. 36, pp. 156-161, 2018.

[67] Tang M., Werner C., Karwowski M., "Differences in Creative Mindset between Germany and Poland: The Mediating Effect of Individualism and Collectivism," Thinking Skills and Creativity, vol. 21, pp. 31-40, 2016.

[68] Bentler P. M., Chou C. P., "Practical Issues in Structural Equation Modeling," Sociological Methods \& Research, vol. 16, pp. 78-117, 1987.

[69] Diehl E. "Motivating students with mindset coaching and how brains work," Classroom 2.0 https://classroom20.com/forum/topics/motivating-students-wi th (accessed October, 7, 2008).

[70] Dweck C. S. "Mindset: The New Psychology of Success," Ballantine Books, 2006.

[71] Boomsma A., Hoogland J. J., "The Robustness of LISREL Modeling Revisited," in Structural Equation Modeling Present and Future, Scientific Software International, 2001, pp. 139-168.

[72] Field A. "Discovering Statistics using IBM SPSS Statistics," Sage, 2013

[73] Jöreskog K. G. "A General Approach to Confirmatory Maximum Liklihood Factor Analysis," Psychometrika, vol 34, no. 2, pp. 183-202, 1969.
[74] Geiser C. "Data Analysis with Mplus," The Guilford Press, 2013.

[75] Kline R. B. "Principles and Practice of Structural Equation Modeling,"3rd ed., The Guilford Press, 2011.

[76] Barron R. M., Kenny D. A., "The Moderator-Mediator Variable Distinction in Social Psychological Research: Conceptual, Strategic and Statistical Consideration," Journal of Personality and Social Psychology, vol. 51, pp. 1173-1182, 1986.

[77] James L. R., Brett J. M., "Mediators, Moderators and Test for Mediation," Journal of Applied Psychology, vol. 69, pp 307-321, 1984

[78] Jose E. P. "Doing Statistical Mediation and Moderation," The Guilford Press, 2013

[79] Dweck C. S. "Mindset, the new psychology of success," Random House, 2016.

[80] Cook D. A. Naik N. D., "Influencing Mindsets and Motivation in Procedural Skills Learning: Two Randomized Studies," Journal of Surgical Education, vol. 76, no. 3, pp. 652-663, 2018.

[81] Degol J. L., Wang M., Zhang Y., Allerton J. "Do Growth Mindsets in Math Benefit Females? Identifying Pathways between Gender, Mindset, and Motivation," Journal of Youth and Adolescence, vol. 47, pp.976-990, 2018.

[82] Bittner J. V., Heidemeier H., "Competitive Mindsets, Creativity, and the Role of Regulatory Focus," Thinking Skills and Creativity, vol. 9, pp. 59-68, 2013

[83] Ryazanov A. A., Christenfeld N. J. S., "Incremental Mindsets and the Reduced Forgiveness of Chronic Failures," Journal of Experimental Social Psychology, vol. 76, pp. 33-41, 2018.

[84] Burrus J., Moore R., "The Incremental Validity of Beliefs and Attitudes for Predicting Mathematics Achievement," Learning and Individual Differences, vol. 50, pp. 246-251, 2016.

[85] Hanson J., Ruff W., Bangert A., "Investigating the Relationship between School Level and a School Ggrowth Mindset," Journal of Educational Issues, vol. 2, no. 2, pp. 203-221, 2016

[86] Son J., Kang C., Kwon O. N., "A Comparative Analysis of the Relationship among Quality Instruction, Teacher Self-Efficacy, Student Background, and Mathematics Achievement in South Korea and the United States," Eurasia Journal of Mathematics, Science \& Technology Education, vol. 12 , no. 7 , pp. 1755-1799, 2016

[87] Stride C. B., Gardner S. E., Catley N., Thomas F. "Mplus code for mediation, moderation, and moderated mediation model," www.figureout.out.uk (accessed May, 7, 2018).

[88] Limeri, L. B., Carter, N. T., Choe, J., Harper, H. G., Martin, H R., Benton, A., Dolan, E. L. (2020). Growing a growth mindset: characterizing how and why undergraduate students' mindsets change. International Journal of STEM Education, vol. 7, no. 35. https://doi.org/10.1186/s40594-02000227-2

[89] Yeager, D. S., Hanselman, P., Walton, G. M., Murray, J. S., Crosnoe, R., Muller, C., Tipton, E., Schneider, B., Hulleman, 
C. S., Hinojosa, C. P., Paunesku, D., Romero, C., Flint, K., Roberts, A., Trott, J., Iachan, R., Buontempo, J., Yang, S. M., Carvalho, C. M., Hahn, P. R., Gopalan, M., Mhatre, P., Ferguson, R., Duckworth, A. L., Dweck, C. S. (2019). A national experiment reveals where a growth mindset improves achievement, Nature, vol. 576, pp. 364-369. https://doi.org/10.1038/s41586-019-1466-y

[90] Dowdy, J. E. The relationship between mindset and motivation in an alternative school mathematics classroom. (Doctoral dissertation). Retrived from https://scholarcommo ns.sc.edu/etd/5285 